\title{
COGNITION AND TRANSDISCIPLINARY DESIGN: AN EDUCATIONAL FRAMEWORK FOR UNDERGRADUATE ENGINEERING DESIGN CURRICULUM DEVELOPMENT
}

\author{
Alyona Sharunova ${ }^{1}$, Mehwish Butt ${ }^{1}$, Suzanne Kresta ${ }^{2}$, Jason Carey ${ }^{1}$,Loren Wyard-Scott ${ }^{3}$, Samer \\ Adeeb $^{4}$, Luciënne Blessing ${ }^{5}$, and A.J. Qureshi ${ }^{l}$. \\ ${ }^{1}$ Department of Mechanical Engineering, ${ }^{2}$ Department of Chemical Engineering, ${ }^{3}$ Department of Electrical and \\ Computer Engineering, ${ }^{4}$ Department of Civil and Environmental Engineering, University of Alberta \\ ${ }^{5}$ Engineering Design and Methodology, Singapore University of Technology and Design \\ ajquresh@ualberta.ca
}

\begin{abstract}
Contemporary engineering product design and development no longer adheres to the boundaries of a single discipline and has become tightly integrated, often relying on interaction of multiple disciplines for completion of integrated product design projects. In order to design these products, design and development practice has transcended the discipline boundaries to become a transdisciplinary engineering design process. A collaboration of specialists from different engineering disciplines is required to develop efficient solutions to interdisciplinary problems of product design. Despite this shift from mono-disciplinary to transdisciplinary, the engineering design curriculum remains focused on teaching discipline specific design practice through skill based subject specific pedagogy with a limited emphasis on the importance of design process and transdisciplinarity in the design process. As a result, new graduates starting in design and development organizations face a difficulty finding a common basis of understanding of disciplines' interactions and must go through a process of often implicit 'onboarding' to understand the transdisciplinary engineering design process. This can be avoided by developing and adapting undergraduate design process education in line with industrial demands. This paper proposes a theoretical framework based on empirical engineering design research in industry, educational psychology and teaching approaches such as Bloom's Taxonomy and Kolb's Model of Experiential Learning for developing the core elements of a transdisciplinary engineering design process curriculum.
\end{abstract}

Keywords: Engineering Design Education, Transdisciplinary Design, Design and Cognition, Design Process, Design Stages, Design States, Bloom's Taxonomy, Kolb's Experiential Learning Model.

\section{INTRODUCTION}

Contemporary product development has transformed from being mono-disciplinary to highly transdisciplinary. A collaboration of specialists from different engineering disciplines is required to develop efficient solutions to interdisciplinary problems of integrated product design [3], [4]. Consider an example of an automobile, which is an integrated transdisciplinary product designed by engineers from mechanical, electrical, chemical and other engineering disciplines and industrial designers. In order to create the most optimal product designs these experts should have a "shared understanding" of the design process and communicate effectively along the way as the lack of understanding may increase the number of iterations in the design process or can result in project failure [9]. In other words, an interdisciplinary competence which includes technical and general skills as well as a thorough knowledge of design processes and expertise is essential for the project's success.

Despite this new reality and industrial demand, engineering design curriculum remains strongly focused on teaching subject specific problem resolution approach of various engineering disciplines. As a result, engineers graduating from different disciplines have limited common basis to relate to the overarching engineering design process and can experience difficulty moving into industry. When recent graduates enter the interdisciplinary workplace, they spend a significant amount of time adapting, adjusting and re-learning their concepts about design in the context of different departments within the company to boost their knowledge and communication levels. In other words, there is a "gap" between the level of knowledge necessary to succeed in a workplace and the level of knowledge provided in academia. The cause of this gap is rooted in the mono-disciplinary nature of current approaches to engineering design pedagogy. Teaching mostly focuses on discipline specific knowledge, often excluding knowledge from other 
engineering disciplines. This can be avoided by developing and adapting a common undergraduate design education in line with transdisciplinary industrial design demands. This paper proposes a theoretical framework based on empirical industrial engineering design process research and educational psychology to develop the core elements of a transdisciplinary engineering design curriculum. The framework is based on transdisciplinary design process commonalities identified in empirical research as well as educational psychology and teaching methodologies such as Bloom's Taxonomy and Kolb's Model of Experiential Learning.

\section{LITERATURE REVIEW}

\subsection{The Design Process Commonalities}

Several empirical studies on transdisciplinary engineering design process in industry have pointed out core similarities in the design process in engineering industry. These studies show that engineers in each domain perform analogous steps when designing the product but using different terminology. For example, "establishing a need" and "defining a problem" are both the same first in the designing activity.

Gericke and Blessing [19], [20] compared different design process models from 9 engineering disciplines and discovered a set of design stages which were similar across disciplines. The following design stages were identified as the most common: establishing a need, analysis of a task, conceptual design, embodiment design, detailed design, implementation, use and closeout. Qureshi et al. [3] performed an empirical study with industrial designers who were part of transdisciplinary teams and identified shared elements of current design practice in industry. The results show that design stages are well-distinguished by participants and that the design process has an iterative nature. This study also pointed to the diversity of terminologies used across different disciplines, which was further supported by the result from a study on analysis of transdisciplinary design processes in the industry by Gericke et al. [20]. In their study on the stages in product lifecycle, Qureshi et al. [4] studied 23 existing engineering companies with different contexts and proposed a stage-based framework for analyzing the transdisciplinary design process which supported the findings of Gericke and Blessing [19] that design stages are similar across engineering domains.

Eisenbart performed a transdisciplinary analysis of 31 design methodologies from 5 disciplines with a focus on design states, which are defined as "the incorporation of all the information about the design as it evolves" [3], [4]. They proposed a list of design states: problem statement, context analysis, need, product idea, product proposal, design object specification, requirements specification, product functionality, working structure, conceptualization, preliminary layout, and production documents.

Based on the series of transdisciplinary industrial studies comprising 17 organizations from 14 different countries on 4 continents, it was shown that experienced design professionals also recognized and worked with a fundamental core of cognitive, creative and logical processes in engineering design and design states that are similar across discipline [3], [20].

Despite the presence of these engineering design process commonalities between engineering disciplines in industry, undergraduate engineering design curriculum remains focused on teaching discipline specific design practice. To facilitate the improvement in communication and mutual understanding among engineering disciplines, we suggest that these results from industrial research be incorporated in teaching practices.

\subsection{Teaching Design}

Finding professional workers and then training them to be effective professionals are two of the biggest concerns of contemporary engineering employers as they seek both job specific and generic skills in their employees [26], [36]. These generic or professional skills include communication, teamwork, creativity, ability to solve problems, critical thinking, etc. Due to concerns raised by corporations and employers that incoming graduates lack fluency in professional skills, several studies were done with an aim to improve contemporary education practice to facilitate the developments of professional skills during undergraduate studies. These approaches include students' motivation to succeed academically [38], project-based learning [6], creativity in engineering education [16], [27], communication and teamwork [26].

Early attempts to restructure academic courses and introduce classroom modifications in the form of community involvement and student teamwork was first done in late 90s and then studied by Old and Millers in 2004 [8]. The results of their study suggested a strong need for experiential learning, or a hands-on experience in teams. It allowed students to learn the material faster, and to practice and develop their communication skills and networking. This further allowed these students to succeed in a workplace more than their peers who did not have that classroom intervention. In other words, the more students are exposed to solving practical close-to-real problems working in diverse teams with other students, the more they develop their professional skills. 
These studies emphasize the importance of development of both students' technical skills, mathematical abilities, and professional skills such as communication, creativity and teamwork. But this development also strongly depends on students' cognitive development. The majority of studies on improving an engineering education are discipline specific, excluding the cross-analysis of all engineering domains [26], [27], [38] and often cover only one or two cognitive attributes but not the whole cognitive domain. Limited research has been carried out on developing design process education frameworks, which account for the transdisciplinary nature of engineering design and consider the cognitive processes in the engineering design process.

Based on the results from the literature review of both industrial and engineering educational research, we see an opportunity for improvement of the current educational state. We suggest the development of an educational framework for curriculum development that teaches students the basics of the design processes and transdisciplinarity in engineering practice as well as develop their interdisciplinary competencies.

\section{TRANSDISCIPLINARY DESIGN EDUCATION FOR ENGINEERING UNDERGRADUATES}

Transdisciplinarity within engineering education is the core element of this paper, the goal of which is to answer the following questions:

- What approach can be taken to ensure that recent graduates possess an appropriate knowledge level required for successful entrance and performance in the contemporary transdisciplinary workplace?

- What methodology can be used to develop an appropriate educational curriculum for engineering undergraduates for teaching transdisciplinary design processes and to develop creativity and interdisciplinary competencies in students?

- What common language can overcome terminology differences between engineering domains?

To keep up with the needs of industry and to account for the development of students' fundamental cognitive, creative, and logical design skills, we suggest a framework based on the transdisciplinary design processes identified in empirical research as well as educational psychology. Figure 1 shows the structure and the flow of development of the proposed framework which starts with the input of results from both industrial and educational research on engineering design, which are analyzed via a literature review. The literature review, discussed in the previous section, pointed out three core elements which should be

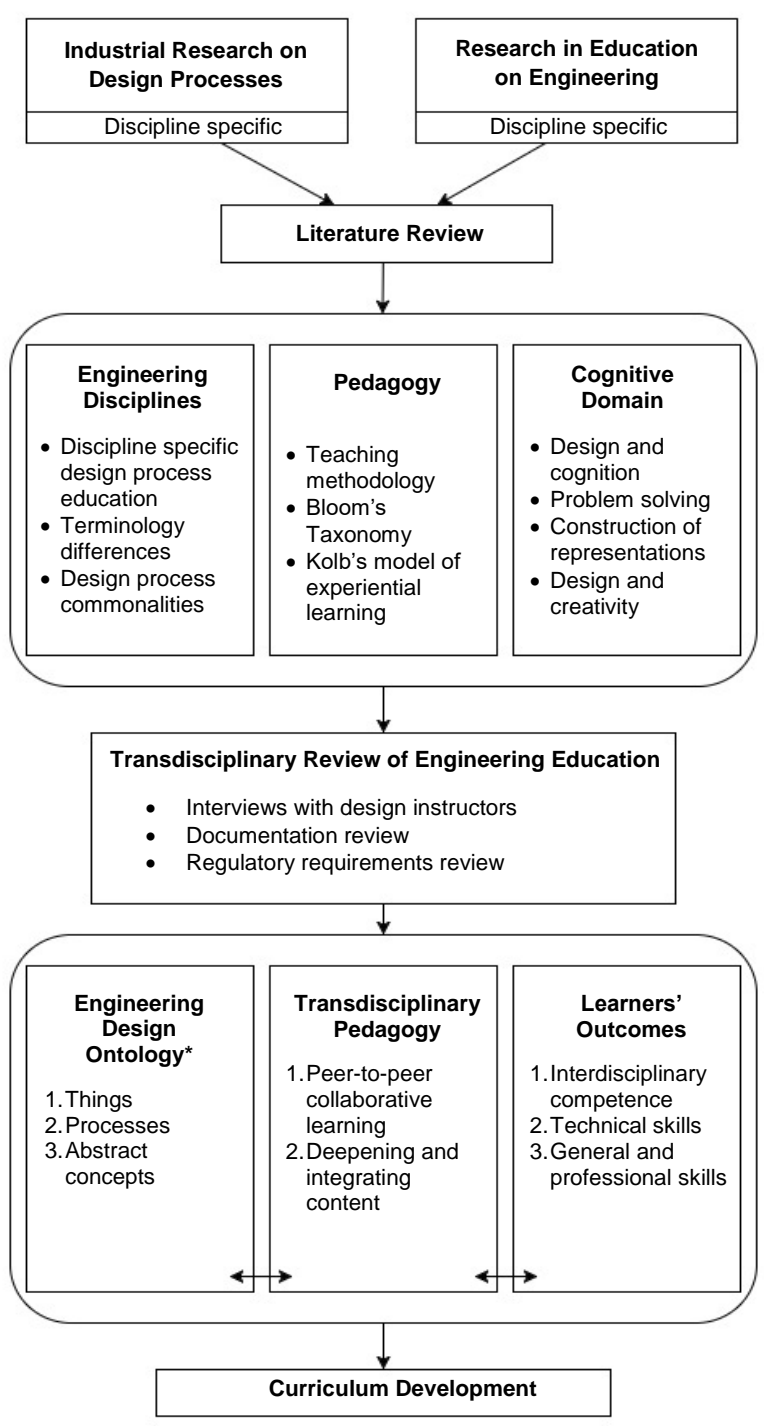

Figure 1. An Educational Framework for Undergraduate Engineering Design Curriculum Development. * [23].

considered in this framework: engineering disciplines, pedagogy, and human cognition.

As has been mentioned above, engineering disciplines teach discipline specific design processes, often excluding the knowledge from other engineering domains, which, due to terminology differences, results in communication gaps among students and young professionals. However, research in industry showed design process commonalities among engineering domains, which are not generally covered in undergraduate engineering design curriculum. The framework aims to analyze teaching content of each discipline and incorporate it in line with industrial design process commonalities. This leads to the next element, the teaching methodology, which is to be revised to ensure that core design process elements are addressed and 
students' cognitive development is accounted for. Bloom's Taxonomy and Kolb's Model of Experiential Learning play a major role in the revision of teaching methodology and will be discussed in the following section. The framework emphasizes the importance of human cognition and cognition in design processes and incorporates the most common perspectives on design such as problem-solving or construction of representations.

These elements are later analyzed together in a transdisciplinary review of engineering design education in line with Canadian academic regulations in engineering education to develop three essential outputs of the framework: 1) engineering design ontology of items, processes and abstract concepts of engineering design to overcome terminology-related communication difficulties between engineering domains, 2) revised transdisciplinary teaching methodology which will facilitate peer-to-peer collaborative learning and deepening of teaching content, and improved 3) learner outcomes in the form of interdisciplinary competence developments in students. These outputs together are to be incorporated into the curriculum of a first-year engineering design course.

\subsection{Bloom's Taxonomy and Kolb's Model of Experiential Learning}

Bloom's Taxonomy, developed by Benjamin Bloom in the mid- $20^{\text {th }}$ century and later revised by his followers, is a set of taxonomies in three domains of learning, namely cognitive, affective and psychomotor [13], [21], [25]. For the purpose of this paper we will focus only on the cognitive domain, which involves conscious intellectual activity [11], [30]. It consists of 6 cognitive levels of complexity: Knowledge, Comprehension, Application, Analysis, Synthesis and Evaluation. Bloom's Taxonomy is a powerful tool for teaching as it provides teachers with a common language to translate and discuss the standards of two different subject areas as well as to understand how these subjects overlap or how to develop conceptual and practical knowledge concurrently [25]. The application of Bloom's Taxonomy in education is strongly linked with development of both high and low levels of thinking, problem solving, creative and critical thinking skills [34]. Since engineering design education is mostly based on teaching students the basics of engineering and then combining this knowledge in design projects, a successful synthesis of knowledge from previous courses is essential in this case and can be achieved through application of Bloom's Taxonomy as a common language.

On the other hand, Kolb's Model of Experiential Learning is based on the works of $20^{\text {th }}$ century educational psychologists such as Lewin, Piaget, James and Jung who played a central role in the creation of human development and learning theories [12]. Experiential learning theory (ELT) is a holistic model of the learning process and multilinear model of adult development, which emphasizes the role of experience in the learning process of every individual. Kolb defined learning as "the process whereby knowledge is created through the transformation of experience. Knowledge results from the combination of grasping and transforming experience" [5]. The ELT model explains two dialectically related modes of grasping experience - Concrete Experience (CE) and Abstract Conceptualization (AC) - and two dialectically related modes of transforming experience Reflective Observation (RO) and Active Experimenting (AE). For Kolb, experiential learning is a cyclic process of knowledge construction involving a creative tension among these learning modes which is responsive to the context. By providing the students with experiences that would lead them through the full cycle, an instructor can create more extensive learning as opposed to focusing on one of the dialectic modes at a time [22]. In other words, just as a combination of academic, personal, professional life experience is essential for complete human development, so is the implementation of teaching methods which would equally focus on all dialectic modes through the course.

Kolb's ETL model is a powerful tool, especially in combination with Bloom's Taxonomy, for the creation of a study space which would facilitate the development of both creativity and interpersonal competencies. This would be done in the form of well-defined academic goals which address both subject matter and cognitive perspectives as well as providing students with experiential learning opportunities to address the affective and psychomotor domains. The proposed framework is applicable to the development of any engineering design course and to support engineering professors as they explore the transdisciplinary nature of design process.

\subsection{Ontology for Engineering Design (Terminology)}

Different engineering disciplines use disciplinespecific design methodologies and terminologies across the domains to design products. These methodologies are taught explicitly or implicitly as a part of the engineering curriculum to undergraduate students. In terms of transdisciplinarity, it is important to have a common framework to effectively capture the differences in terminology and to establish a common generic engineering design process which is applicable across all disciplines.

We propose integrating ontology in the framework. Ontology is defined as "a formal explicit specification of conceptualization" [7]. It classifies and categorizes design 
functions and concepts according to their intrinsic and extrinsic properties.

Most of the research done in ontology till date has captured domain specific knowledge and terminologies since the relationship between the components of a functional model is governed by user-specific requirements which are always domain dependent and therefore follow a certain behavior. These functional models are abstract and difficult to synthesize and create a lot of confusion while defining a generic design process [23].

To overcome the terminology barrier across disciplines, formal ontologies are designed. Formal ontologies should possess, as minimum few characteristics: clear definition and coherence, representative irrespective of their subjective implementation, and ontologically committed [33]. Ontologies are formalized through ontological commitment by using shared vocabulary in a consistent manner across multiple domains [32]. Ontology commitments describe certain conditions called operands, which bound the entities that constitute a design process. Gero presented function-behavior-structure (FBS) ontologies to describe the properties of objects as well as processes by defining the attributes and relations of the entities in terms of their functions, behaviors and structures [17]. They presented a generic structure of a process composed of components which can have multiple views when described in terms of their function, behavior and structure. The FBS ontology for a process can be generalized for multiple kinds of production, manufacturing, computing and other processes. The process models are distinguished from the others through state and kind of inputs and the transformations which occur from initial input stage till the final output stage.

Since our framework intends to design a transdisciplinary engineering design curriculum, where information capture across multiple disciplines is the goal, the focus is always to adapt a generic ontology which is inclusive of the knowledge of all the individual disciplines. For this reason, a transdisciplinary ontology for engineering design will be built to organize knowledge from each discipline in a formal and more generic way. An engineering ontology contains both generic and product specific elements [29]. Significant research has been done to define ontologies based on their use and limitations [7], [28] which propose that these ontologies can be used independently or collectively. In case none of the existing ontologies fit in the purpose a new ontology can be generated.

Many authors have presented the building scheme of an engineering ontology [29], [24]. The general ontology building process consists of following stages: organizing and scoping, data collection, data analysis, initial ontology formation, ontology refinement and evaluation.
These stages are organized and can be taken as a base model to design the ontology. Some authors have proposed the building process of general design ontology by developing associations between entities using Suggested Upper Merged Ontology (SUMO) by IEEE at different physical and abstract levels [23]. A structured approach is described to form and implement the proposed design ontology for multiple processes by following a generic structure framework. The vocabulary proposed for design ontology describes entities in terms of objects, process and abstract concepts. The vocabulary is generic and can be applied to a broad range of domains. A similar approach may be used to develop the transdisciplinary education framework.

The resulting ontology from transdisciplinary review shall serve the following purposes: 1) conceptualize the generic design process, 2) define key stages in the generic design process, 3) classify entities, their attributes, purpose and relations and 4) inter-relate design stages within and across multiple disciplines with respect to their key attributes. The use of ontology in the proposed educational framework shall bring homogeneity across engineering domains by successfully covering the terminology barrier and shall aid in teaching methodologies.

\section{DESIGN AND COGNITION: PERSPECTIVES ON DESIGN}

To teach design to others, one should clearly understand what design is. To develop our framework, we explore design from the cognitive perspective. Design and designing activity has been a continuing concern of psychologists as it is related to the basic human cognitive abilities such as problem-solving, decision making, critical thinking, creativity, etc., which are all framed as an essential part of interdisciplinary competence expected by employers.

\subsection{Design as Problem-Solving}

An ability to solve problems is considered as an important outcome of any undergraduate studies [14] and has a critical role in engineering education. Most of the problems presented in science and engineering courses are well-structured, providing students with a well-defined problem and asking to implement a series of steps to reach the solution. Problems such as solving a quadratic equation or applying a theorem have little input of higher cognitive functions like problem-solving and creativity. However, real-life industrial engineering design problems are complex and ill-defined, requiring application of advanced cognitive abilities, which is why it is important 
to account for the development of such abilities in students during their undergraduate studies.

In engineering design courses students are often given projects with unstructured problems, or examples of actual industrial projects, and are expected to find the most efficient solutions. Designing in engineering is not a simple problem-solving as one cannot find the effective problem solution without understanding the problem first and cannot choose the most satisfying solution without considering product requirements. In cognitive psychology, a problem-solving of ill-defined problems is generally described as step-like process: 1) defining the problem, 2) generating a variety of solutions, and, 3) executing the solution [10], [35], which is similar to the design process described in industrial research. But the ability to solve problems also strongly relies on students' prior knowledge of the course (or, few other courses) as well as their ability to think critically, making decisions and defending their choices as poorly designed engineering products may result in serious consequences. In other words, higher levels of knowledge such as Analysis, Synthesis, and Evaluation of Bloom's Taxonomy are required for successful problem-solving. Also, an ability to apply a strategy or solve a problem step-by step is important in engineering education as the design process is a stage-like process nature [15]. In addition, experiential intelligence, an ability to solve new problems based on the prior experiences with similar problems, contributes to the development of creativity in students as they shift from being novices to experts [10], and so it is important for interdisciplinary competence advancement and developed during undergraduate design education.

\subsection{Design as a Construction of Representations}

Many design definitions focus on the outcome of the design activity, the final product, rather than on the process itself, but designing is a creation process and can also be defined as a "construction of representations" [35]. In her book, The Cognitive Artifacts of Designing, Visser says that designers do not produce the artifact product, rather they produce specifications, which are necessary to manufacture the product and ensure that the product meets certain functions. Visser defines design as a process of specifying an artifact, given requirements, that indicate certain functions to be fulfilled and needs to be satisfied by the artifact. On a cognitive level, this activity consists of constructing precise, concrete, and detailed representations of the artifact which explicitly and completely specify the implementation of the artifact. The construction process is iterative as many intermediate representations are generated, transformed and evaluated before the final result is achieved, which is exactly what designers do in practice while designing, testing and trying different versions of the design before the most pleasing one is found. Representations are cognitive tools that help keeping track of ideas, advance understanding and "see" things differently, discover new ideas, organize "work", communicate ideas to other, etc. [35]. However, to do so they have to be transferred into physical or external form, sketches, samples, graphic documentation [1], [18].

In a sense of artistic creation, there is a difference between "design" and "creation" which lies in the presence of specified design characteristics of the outcome. Creativity, defined as an ability to produce something new and unexpected or to solve a problem in an extraordinary or simpler way, is an essential cognitive ability which plays a role in product novelty and originality [31]. This sudden mental insight, which leads to creation of unusual problem solutions, is considered as an essential characteristic of design. Creation may be artistic and creative but not necessarily follow specific guidelines. Designing, on the other hand, has a purpose to fulfil given product specifications, which should be precise and clear enough so that other designers could be able to implement them.

A perspective on design similar to the two discussed above, which is also accounting for the importance of product specifications but in technical terms, is discussed in classical constrained satisfaction (CSP) model used widely for resolution of problems including the design problems in the field of mechanical engineering [2]. It defines design as a process of "constraint identification and satisfaction. The process of constraint satisfaction is complex, because coupling between the constraints hinders the process of searching for a feasible design. A design problem can be viewed as constraint satisfaction problem in which the designer aims to find a solution to the key product parameters such as the functional requirements as stipulated by the client needs are satisfied".

In engineering design, an ability to produce clear, precise and detailed product representations is essential to produce technical design, and understanding of the cognitive processes underlying the design activity must be accounted for successful teaching of design.

\section{IMPLEMENTATION AND CONCLUSION}

Understanding the cognitive processes responsible for the design activity in human mind is essential for teaching design, understanding the design process itself as well as how to improve teaching it to students to enhance and develop their cognitive abilities and interdisciplinary competence is the purpose of the framework proposed in this paper. This theoretical framework incorporates the empirical research in industry on engineering design processes and educational psychology approaches to 
identify the core elements of a transdisciplinary engineering design curriculum. Revised current teaching methodologies as well as supporting educational approaches such as Bloom's Taxonomy and Kolb's Model of Experiential Learning will also be incorporated in the final framework. Students' cognitive development is emphasized in this framework as an essential part of the learning processes. The outcomes of the framework are: an engineering design ontology, which serves as a solution to the terminology differences between engineering disciplines; transdisciplinary pedagogy to teach the engineering design process commonalities and the idea of transdisciplinarity in engineering industry, and development of students' interdisciplinary competence and professional skills.

The framework will be based on a detailed review of the current design education at a leading Canadian university. The results will be benchmarked against existing national and international design education programs and will be incorporated in an educational framework applicable to undergraduate engineering design courses in order to provide students fundamental cognitive, creative, and logical design skills. Together, these outcomes will be incorporated in engineering design curriculum development of the first-year engineering design course. These will allow students to appreciate the integrated broader nature of contemporary engineering design and will prepare them for a successful insertion in a rapidly evolving industry that transcends multiple disciplines.

\section{References}

[1] A. T. Purcell and John S. Gero, "Drawings and the design process," Design Studies, vol. 19, no. 4, pp. 389-430, 1998.

[2] Ahmed J. Qureshi, Jean-Yves Dantan, Jerome Bruyere, and Regis Bigot, "Set based robust design of mechanical systems using the quantifier constraint satisfaction algorithm," Engineering Applications of Artificial Intelligence, vol. 23, pp. 1173-1186, 2010.

[3] Ahmed J. Qureshi, Kilian Gericke, and Lucienne M. Blessing, "Design Process Commonalities in TransDisciplinary Design," in ICED13: 19th International Conf. on Engineering Design, (Seoul, Korea; 19-22 August 213), 10 pp., 2013.

[4] Ahmed J. Qureshi, Kilian Gericke, and Lucienne M. Blessing, "Stages in product lifecycle: Trans-disciplinary design context," Procedia CIRP, vol. 21, pp. 224-229, 2014.

[5] Alice Y. Kolb and David A. Kolb, "Learning Styles and Learning Spaces: Enhancing Experiential Learning in Higher Education," Academy of Management Learning and Education, vol. 4, no. 2, pp. 193-212, 2005.

[6] Angela R. Bielefeldt, Kurtis G. Paterson, and Christopher W. Swan, "Measuring the Value Added from ServiceLearning in Project-Based Engineering Education,"
International Journal of Engineering Education., vol. 26 , no. 3, pp. 535-546, 2010.

[7] Asuncion Gomez-Perez and Richard V. Benjamins, "Overview of Knowledge Sharing and Reuse Components: Ontologies and Problem-Solving Methods," in Proc. IJCAI-99 workshop on Ontologies and Problem-Solving Methods (KRR5), (Stockholm, Sweden; 2 August 1999) 15 pp., 1999.

[8] Barbara M. Olds and Ronald L. Miller, "The effect of a firstyear integrated engineering curriculum on graduation rates and student satisfaction: A longitudinal study," Journal of Engineering Education, vol. 93, no. 1, pp. 23-35, 2004.

[9] Boris Eisenbart, Kilian Gericke, and Lucienne Blessing, "A Framework for Comparing Design Modelling Approaches Across Disciplines," in Proc. International Conf. on Engineering Design, ICED11, (Denmark; 15-18 August 2011), 12 pp., 2011.

[10] Daniel L. Schacter, Daniel T. Gilbert, and Daniel M. Wegner, Psychology: Custom Edition for University of Alberta. New York, NY: Worth Custom Publishing, 2008.

[11] Darcy H. Granello, "Encouraging the cognitive development of supervisees: Using Bloom's Taxonomy in supervision," Counselor Education and Supervision, vol. 40, no. 1, pp. 31-46, 2000.

[12] David A. Kolb, Richard E. Boyatzis, and Charalampos Mainemelis, "Experiential Learning Theory: Previous Research and New Directions", in R. Stenberg and L. Zhang (ed.), Perspectives on cognitive, learning and thinking styles, NJ: Lawrence Erlbaum, 2000.

[13] David Krathwohl, “A Revision of Bloom's Taxonomy: An Overview," Theory into Practice, vol. 41, no. 4, 2002.

[14] Diana Laurillard, "Styles and Approaches in Problemsolving," in The Experience of Learning: Implications for Teaching and Studying in Higher Education, Edinburgh: University of Edinburgh, Centre for Teaching, Learning and Assessment (2rd ed.), F. Marton, D. Hounsell, and N. Entwistle, (ed.), pp. 126-144, 2005.

[15] Donald R. Woods, "An Evidence-Based Strategy for Problem Solving," Journal of Engineering Education, vol. 89, no. 4, pp. 443-459, 2000.

[16] Job. V. Kuruvilla and B. Mukhopadhyay, "Epistemological Study to Evolve Creative Learning Process for Engineering Students," Journal of the Indian Academy of Applied Psychology, vol. 34, Special issue, pp. 101-109, 2008.

[17] John S. Gero and Udo Kannengiesser, "A function behavior - structure ontology of processes," Artificial Intelligence for Engineering Design, Analysis and Manufacturing, vol. 21, pp. 379-391, 2007.

[18] John S. Gero, "Design Prototypes: A Knowledge Representation Schema for Design," AI Magazine, vol. 11, no. 4, p. 26-36, 1990.

[19] Kilian Gericke and Lucienne Blessing, "An Analysis of Design Process Models Across Disciplines," in Proc. International Design Conf. - Des. 2012, (Dubrovnik, Croatia; 21-24 May 2012), 9 pp., 2012.

[20] Kilian Gericke, Lucienne M. Blessing, and Ahmed J. Qureshi, "Analyzing Transdisciplinary Design Processes in Industry - An Overview," in Proc. ASME 2013 International Design Engineering Technical Conf. and Computers Information in Engineering Conf. IDETC/CIE 2013, (Portland, Oregon; 4-7 August 2013), 11pp., 2013. 
[21] Lorin W. Anderson and David Krathwohl, “A Taxonomy for Learning, Teaching, and Assessing: A Revision of Bloom's Taxonomy of Educational Objectives," Educational Horizons, vol. 85, no. 313, pp. 154-159, 2005.

[22] Marilla D. Svinicki and Nancy M. Dixon, "The Kolb Model Modified for Classroom Activities," College Teaching, vol. 35, no. 4, pp. 141-146, 1987.

[23] Mario Storga, Mogens M. Andreasen, and Dorian Marjanovic, "The design ontology: foundation for the design knowledge exchange and management," Journal of Engineering Design, vol. 21, no. 4, pp. 427-454, 2010.

[24] Mario Storga, Mogens M. Andreasen, and Dorian Merjanovic, "Towards a Formal Design Model Based on a Genetic Design Model System," in Proc. International Conf. on Engineering Design ICED 2005, (Melbourne; 1518 Augusy 2005), 15 pp., 2005.

[25] Mary Forehand, "Bloom's taxonomy: Original and revised," in M. Orey (Ed.), Emerging perspectives on learning teaching, and technology, pp. 1-9, 2005.

[26] Mohd Z. Kamsah, "Developing Generic Skills in Classroom Environment Engineering Students' Perspective," in Proc. Conf. on Engineering Education (CEE 2004), 6pp., 2004.

[27] Nicolai P. Kirillov, Elena G. Leontyeva, and Yulia A. Moiseenko, "Creativity in Engineering Education," Procedia - Social Behavioral Sciences, vol. 166, pp. 360363, 2015.

[28] Saeema Ahmed and Mario Storga, "Merged ontology for engineering design: Contrasting empirical and theoretical approaches to develop engineering ontologies," Artificial Intelligence for engineering Design, Analysis and Manufacturing, vol. 23, pp. 1-17, 2009.

[29] Saeema Ahmed, Sanghee Kim, and Ken M. Wallace, “A Methodology for Creating Ontologies for Engineering Design,' Journal of Computing and Information Science in Engineering, vol. 7, no. 2, pp. 132-140, 2007.

[30] Stephen C. Betts, "Teaching and Assessing Basic Concepts to Advanced Applications: Using Bloom's Taxonomy to Inform Graduate Course Design," Academy of Educational Leadership Journal, vol. 12, no. 3, pp. 99-106, 2008.

[31] Tapio Takala, "A Neuropsychologically-Based Approach to Creativity," In J. S. Gero and M. L. Maher Modeling Creativity and Knowledge-Based Creative Design, Hillsdale, NJ: Lawrence Erlbaum Associates, 1993, pp. 91108.

[32] Thomas R. Gruber and Gregory R. Olsen, "An Ontology for Engineering Mathematics," in Proc. Fourth International Conf. on Principles of Knowledge Representation and Reasoning, Jon Doyle, Piero Toraso, and Erik Sandewall (ed.) (Bonn, Germany; 1994), 18 pp., 1994.

[33] Thomas R. Gruber, "A translation approach to portable ontology specifications," Knowledge Acquisition, vol. 5, no. 2, pp. 199-220, 1993.

[34] Toni Noble, "Integrating the Revised Bloom's Taxonomy with Multiple Intelligences: A Planning Tool for Curriculum Differentiation," Teachers College Record, vol. 106, no. 1, pp. 193-211, 2004.
[35] Willemein Visser, The cognitive artifacts of designing. Mahwah: Lawrence Erlbaum Associates, Publishers, 2006, $264 \mathrm{pp}$.

[36] Ying Huang, “Improving Engineering Students' NonTechnical Professional Skills and Attitudes to Engineering Through Inquiry Based Lab Learning, ” Ph.D. dissertation, Michigan State University, 2014.

[37] Yoshinobu Kitamura, Masakazu Kashiwase, Masayoshi Fuse, and Riichiro Mizoguchi, "Deployment of an ontological framework of functional design knowledge," Advanced Engineering Informatics, vol. 18, pp. 115-127, 2004.

[38] Zahed Siddique and Patricia L. Hardre, "Structuring Engineering Design Courses to Motivate Students," in Proc. ASME 2013 International Design Engineering Technical Conferences and Computers and Information in Engineering Conf. IDETC/CIE 2013, (Portland, Oregon; 47 August 2013) 10 pp., 2013. 